\title{
Increasing cardiopulmonary emergency visits by long-range transported Asian dust storms in Taiwan
}

\author{
Chang-Chuan Chan ${ }^{\mathrm{a}, *}$, Kai-Jen Chuang ${ }^{\mathrm{a}}$, Wen-Jone Chen ${ }^{\mathrm{b}}$, Wei-Tien Chang ${ }^{\mathrm{b}}$, \\ Chung-Te Lee ${ }^{\mathrm{c}}$, Chi-Ming Peng ${ }^{\mathrm{d}}$ \\ ${ }^{a}$ Institute of Occupational Medicine and Industrial Hygiene, College of Public Health, National Taiwan University, Rm. 722, \\ No.17, Xu-Zhou Rd., Taipei 100, Taiwan \\ ${ }^{\mathrm{b}}$ Department of Emergency Medicine, National Taiwan University Hospital and College of Medicine, Taiwan \\ ${ }^{\mathrm{c}}$ Graduate Institute of Environmental Engineering, National Central University, Taiwan \\ ${ }^{\mathrm{d}}$ WeatherRisk Explore Inc. Hospital, Taiwan
}

Received 7 June 2007; received in revised form 28 August 2007; accepted 12 September 2007

Available online 23 October 2007

\begin{abstract}
This study aims to explore whether Asian dust storms can affect health after $4000 \mathrm{~km}$ long-range transport from their origins to downwind areas. Asian dust storms reaching Taipei, Taiwan are tracked by satellite images and confirmed by backward trajectory analysis and ground air pollution monitoring between 1995 and 2002. Our outcome variables include emergency visits for ischaemic heart diseases (ICD-9-CM 410-411, 414), cerebrovascular diseases (ICD-9-CM 430-437), and chronic obstructive pulmonary diseases (COPD) (ICD-9-CM 493, 496) from the National Taiwan University Hospital (NTUH). We use simple paired $t$-test and Poisson regression models to compare difference in emergency visits, air pollution levels and meteorological conditions for the pairs of Asian dust events and pre-dust periods. There were 39 high dust events with $\mathrm{PM}_{10}$ greater than $90 \mu \mathrm{g} / \mathrm{m}^{3}$ and another 46 low dust events with $\mathrm{PM}_{10}$ less than $90 \mu \mathrm{g} / \mathrm{m}^{3}$. Compared to their pre-dust periods, $\mathrm{PM}_{10}$ concentrations are significantly increased by $77 \mu \mathrm{g} / \mathrm{m}^{3}$ per event for the high dust events. Asian dust storms increase cardiopulmonary emergency visits during storm-affecting periods in Taipei when ambient PM $\mathrm{M}_{10}$ concentrations are above $90 \mu \mathrm{g} / \mathrm{m}^{3}$. Compared to their pre-dust periods, emergency visits for ischaemic heart diseases, cerebrovascular diseases, and COPD during high dust events are increased by 0.7 case $(35 \%), 0.7$ case $(20 \%)$, and 0.9 case $(20 \%)$ per event, respectively, by paired $t$-tests. By comparing the model-predicted to the observed emergency visits, we find emergency visits for cardiovascular diseases (ICD-9-CM 410-411, 414, 430-437) were significantly increased by 2.9 cases (67\%) per event for the 39 high Asian dust events. (C) 2007 Elsevier Inc. All rights reserved.
\end{abstract}

Keywords: Asian dust storm; Air pollution; Particulate matter; Emergency visit; Epidemiology

\section{Introduction}

It is known that dust derived from mineral soil cause major long-range transported air pollution across many countries in the world. Two major global dust storms annually transport millions of tons of dust from the dustoriginated places to their downwind areas. The African dust storms, which are originated mostly from Sahara in winter and spring seasons and Sahel in summer and autumn seasons, are routinely carried up the Mediterra-

\footnotetext{
${ }^{*}$ Corresponding author. Fax: +886223222362.

E-mail address: ccchan@ntu.edu.tw (C.-C. Chan).
}

nean and European areas, and sometimes even further to the Americas (Moulin et al., 1997). Asian dust storms that occur in spring mainly originate in the Gobi and Takla Makan deserts in Mongolia and western China, and can be transported eastward to China (Chen et al., 2003), Japan (Fan et al., 1996; Var et al., 2000), Korea (Chung and Yoon, 1996), Taiwan (Lin, 2001), and sometimes the western coast of North America (Duce et al., 1980; Husar et al., 2001). Previous studies reported that dust in the storms was transported to the oceans and contributed significantly to deep-sea sediments (Duce et al., 1980; Moulin et al., 1997). A few studies also showed that dust storms from the Sahara could spread fungi or bacteria and 
destroyed Caribbean coral reefs (Shinn et al., 2000; Garrison et al., 2003). Some studies reported that the levels of particulate air pollution, such as total suspended particulate (TSP) (Chung and Yoon, 1996) and particulate matter with aerodynamic diameter less than $10 \mu \mathrm{m}\left(\mathrm{PM}_{10}\right)$ (Var et al., 2000; Husar et al., 2001; Lin, 2001) could rise significantly in the affected urban areas during Asian dust storm periods.

However, there were no consistent findings of adverse health effects corresponding to such increase in particulate pollution in previous health studies. By using mortality data as health outcomes, two studies have found insignificant impacts of Asian dust storms on mortality in Korea and Taiwan. Kwon et al. (2002) reported that Asian dust storms during 1995-1998 were not associated with deaths for cardiovascular (International Classification of Disease 10th revision (ICD-10) I00-I99) and respiratory diseases (ICD-10 J00-J98) in Seoul, Korea. Chen et al. (2004) reported that Asian dust storms during 1995-2000 did not increase the risk of daily mortality of circulatory (International Classification of Disease 9th revision (ICD-9) 390-459) and respiratory diseases (ICD-9 460-519) in Taipei, Taiwan. By contrast, increase in hospital visits for primary intracerebral hemorrhagic stroke visits (ICD-9 431-432) (Yang et al., 2005 ) but not cardiovascular diseases (ICD-9 410-429) (Chen and Yang, 2005) during Asian dust storms were reported in morbidity studies of Taipei, Taiwan. We believe one main reason why Asian dust storms had either no associations with mortality or inconsistent associations with hospital admissions is that both affected areas and periods during the Asian dust storms are not well documented in previously cited studies. Because of short duration and favorable weather conditions, not all Asian dust storms can deteriorate local air quality significantly when they reach downwind areas. The storm with a length of stay less than 1 day or terrestrial rains during the storm periods can reduce an Asian dust storm's impact on the particulate matters' concentrations in the storm-affecting areas. Apparently, whether Asian dust storms can have acute health effects on people living in the downwind areas after their long-range transport from the originating areas remains an unsolved but important public health issue in Asia.

In the past few years, we have conducted a series of studies to explore the adverse effects on air quality and health from long-range transported Asian dust storms in Taiwan. Our air quality monitoring data showed the significant increases in particulate air pollution, sulfate, and organic carbon (OC) during storm-affecting days (Taiwan Environmental Protection Agency, 2002a). In the meantime, our panel study found that urban air pollution could increase coagulation factor of plasma fibrinogen and fibrinolytic factor of plasminogen activator inhibitor-1 (PAI-1) levels in patients with or at risk for cardiovascular diseases (Su et al., 2006). Furthermore, our in vivo study reported concentrated ambient particles (CAPs) collected in Taipei during Asian dust storm were capable of inducing inflammation in the lung and in peripheral blood in rat (Lei et al., 2004). Such findings lead us to hypothesize that Asian dust storms should be able to induce adverse health effects in humans. This study attempts to shed light on such an important public health issue in Asia, where crossboundary air pollution problems are increasing in recent years, by using consistent and good health outcomes data and well-defined temporal and spatial patterns of the Asian dust storms in Taipei, one of their downwind areas, between 1995 and 2002 .

\section{Materials and methods}

\subsection{Asian dust events in Taipei}

Taiwan, located in eastern Asia and off the southeastern coast of China $\left(23^{\circ} 30^{\prime} \mathrm{N}, 121^{\circ} 00^{\prime} \mathrm{E}\right)$, is approximately $4000 \mathrm{~km}$ away from the originating areas of Asian dust storms. The Taipei Metropolitan, with a population of about 6 million, is located in northern Taiwan (Department of Statistics, 2005). When an Asian dust storm reached Taipei, Taiwan Environmental Protection Agency (TEPA) first obtained real-time information about any significant dust storms originating in the deserts of Mongolia and western China from the ground observation stations of yellow dust in China through cross-country cooperation. Then, the Taiwan Central Weather Bureau provided satellite images from MODIS, a moderate resolution imaging spectroradiometer flying on-board the Terra or Aqua satellite, to assist TEPA track the dust storms' paths in East Asia. In the meantime, TEPA also applied backward trajectory analysis to statistically estimated air mass movements in Taipei at different heights in $1 \mathrm{~h}$ to 5-day intervals by using the ARL HYSPLIT Model of the U.S. National Ocean and Atmospheric Administration (NOAA) and the global wind data from the National Centers for Environmental Prediction (NCEP) reanalysis datasets (http://www.arl.noaa.gov/ready/hysplit4.html). Therefore, the traveling paths of Asian dust storms tracked by satellite images were then re-confirmed by the backward trajectory analysis. Last but not least, the air quality measured by three types of air monitoring stations in northern Taiwan was used to define the period of Asian dust storms in Taipei (Table 1). TEPA used Taipei's two background air monitoring stations, Wanli and Yangming, to detect whether there was a significant increase in hourly $\mathrm{PM}_{10}$ concentrations above $100 \mu \mathrm{g} / \mathrm{m}^{3}$ in either one from their normal range of $10-50 \mu \mathrm{g} / \mathrm{m}^{3}$ year round. Wanli station is a coastal monitoring station located at $27 \mathrm{~m}$ above sea level and $25 \mathrm{~km}$ north of Taipei. Yangming station is a mountain station located at $850 \mathrm{~m}$ above sea level and $15 \mathrm{~km}$ north of Taipei. In addition, the averaged hourly $\mathrm{PM}_{10}$ concentration of 3 randomly selected stations among all 16 TEPA-operated air monitoring stations within the Taipei metropolitan area must be higher than $100 \mu \mathrm{g} / \mathrm{m}^{3}$. These 16 air monitoring stations spread around the Taipei metropolitan area continuously measured hourly $\mathrm{PM}_{10}$, particulate matter with aerodynamic 
Table 1

The main characteristic of air monitoring stations

\begin{tabular}{|c|c|c|c|c|}
\hline Characteristic & Wanli & Yangming & $\begin{array}{l}16 \text { TEPA-operated air monitoring } \\
\text { stations }\end{array}$ & Supersite \\
\hline Station type & $\begin{array}{l}\text { Coastal background air } \\
\text { quality }\end{array}$ & $\begin{array}{l}\text { Mountain background air } \\
\text { quality }\end{array}$ & General and traffic air quality & Traffic air quality \\
\hline $\begin{array}{l}\text { Distance to } \\
\text { main road }\end{array}$ & $100 \mathrm{~m}$ & $500 \mathrm{~m}$ & $1-100 \mathrm{~m}$ & $50 \mathrm{~m}$ \\
\hline $\begin{array}{l}\text { Height of } \\
\text { sampling inlet }\end{array}$ & $28 \mathrm{~m}$ & $855 \mathrm{~m}$ above sea level & $4.4-17.3 \mathrm{~m}$ & $4.5 \mathrm{~m}$ \\
\hline
\end{tabular}

$\mathrm{CH}_{4}$, methane; $\mathrm{CO}$, carbon monoxide; $\mathrm{PM}_{2.5}$, particulate matter less than $2.5 \mu \mathrm{m}$ in diameter; $\mathrm{PM}_{10}$, particulate matter less than $10 \mu \mathrm{m}$ in diameter; $\mathrm{NMHC}$, nonmethane hydrocarbons; $\mathrm{NO}_{x}$, nitrogen oxides; $\mathrm{NO}$, nitrogen oxide; $\mathrm{NO}_{2}$, nitrogen dioxide; $\mathrm{O}_{3}$, ozone; $\mathrm{SO}_{2}$, sulfur dioxide; TEPA, Taiwan Environmental Protection Agency; and THC, total hydrocarbon.

diameter less than $2.5 \mu \mathrm{m}\left(\mathrm{PM}_{2.5}\right)$, nitrogen dioxide $\left(\mathrm{NO}_{2}\right)$, sulfur dioxide $\left(\mathrm{SO}_{2}\right)$, carbon monoxide $(\mathrm{CO})$, ozone $\left(\mathrm{O}_{3}\right)$ concentrations, temperature (TP), dew point temperature (DEW), and daily difference temperature (DTP) since 1994. Daily air quality data were summarized by 24-h arithmetic averages of TP, DEW, DTP, $\mathrm{PM}_{2.5}, \mathrm{PM}_{10}$, $\mathrm{NO}_{2}$, and $\mathrm{SO}_{2}$ concentrations, and maximum values of 8-h $\mathrm{CO}$ concentrations and $1-\mathrm{h} \mathrm{O}_{3}$ concentrations for each monitoring station. Air pollution and temperature data were measured at all 16 monitoring stations except $\mathrm{PM}_{2.5}$, which was monitored at two stations. Daily measurements from these multiple monitors were averaged to generate an overall exposure estimate for the population in Taipei. By using yellow dust ground observation, forward satellite tracking and backward trajectory analysis of air mass movements, and ambient particulate measurements described above, we could define an "Asian dust event" and describe air quality during the storm-affecting period in Taipei. We then matched each dust event with a "pre-dust period" of the same duration 1 week before the event in order to determine whether air quality in Taipei significantly deteriorated during the storm-affecting periods.

\subsection{PM components during dust events}

In addition, to compare particulate and gaseous air pollution from 16 TEPA monitoring stations, we obtained PMs size distributions and components for the 2002 Asian dust events and their pre-dust periods from a TEPA-operated particulate matter Supersite monitoring station in Taipei (Table 1). The Taipei Supersite is located in the center of the metropolitan area, and measures hourly air pollution levels of sulfate $\left(\mathrm{SO}_{4}^{2-}\right)$, nitrate $\left(\mathrm{NO}_{3}^{-}\right)$, OC, elemental carbon (EC) and 10-min particle volume concentrations with size resolution between 0.1 and $10 \mu \mathrm{m}$ (PCASP-X; Particle Measuring Systems Inc., Denver, Colorado) continuously since March 1, 2002.

\subsection{Emergency visits for diseases}

The emergency visits data from the National Taiwan University Hospital (NTUH) were used as outcome variables in this study. NTUH is a major medical center with 2000 beds and serves as a major emergency care center for all residents in the Taipei metropolitan area, of which the population was approximately 6 million during the study. We obtained electronic medical records of daily emergency visits for cardiovascular diseases and severe respiratory diseases defined by the ICD-9 from 1995 to 2002. PM is associated with hospital admission for cardiopulmonary diseases, i.e. ischaemic heart diseases, cerebrovascular diseases and chronic obstructive pulmonary diseases (COPD) in a previous study (Dominici et al., 2006). Accordingly, we used the emergency visits data in our analyses that included the patients who were admitted to NTUH with a primary discharge diagnosis of ischaemic heart diseases (ICD-9-CM 410-411, 414), cerebrovascular diseases (ICD-9-CM 430-437), and COPD (ICD-9-CM 493, 496). Each medical record included a patient's visit date, age, sex, and address in addition to discharge diagnoses. Daily emergency visits data for cardiovascular diseases (ICD-9-CM 410-411, 414, 430-437) were matched with available air pollution data between 1995 and 2002 to perform time-series analysis. In addition, event-averaged emergency visits data were calculated by using daily emergency visit data for all pairs of Asian dust events and their pre-dust periods to explore possible association between adverse health effects and storms-induced $\mathrm{PM}_{10}$ in Taipei.

\subsection{Statistical methods}

Two-tail paired $t$-test was used to compare environmental data and emergency visits data from 1995 to 2002 between dust events and their pre-dust periods. We further used the 8-year environmental and emergency visits data to construct a Poisson regression model to predict daily emergency visits for cardiovascular diseases without Asian 
dust storms by considering year, month, day-of-week, TP, DTP, and air pollutants, which were significantly associated with emergency visits in the single-pollutant models. Our base model contains long-term trend of year and month, and short-term temporal variation of day-of-week.
Single-pollutant models were built by adding to the base Poisson model with air pollution levels for each of six air pollutants lagged 0-7 days one by one. The air pollutants, whose odds ratios (ORs) and 95\% confidence intervals (CIs) for interquartile range (IQR) changes in pollution

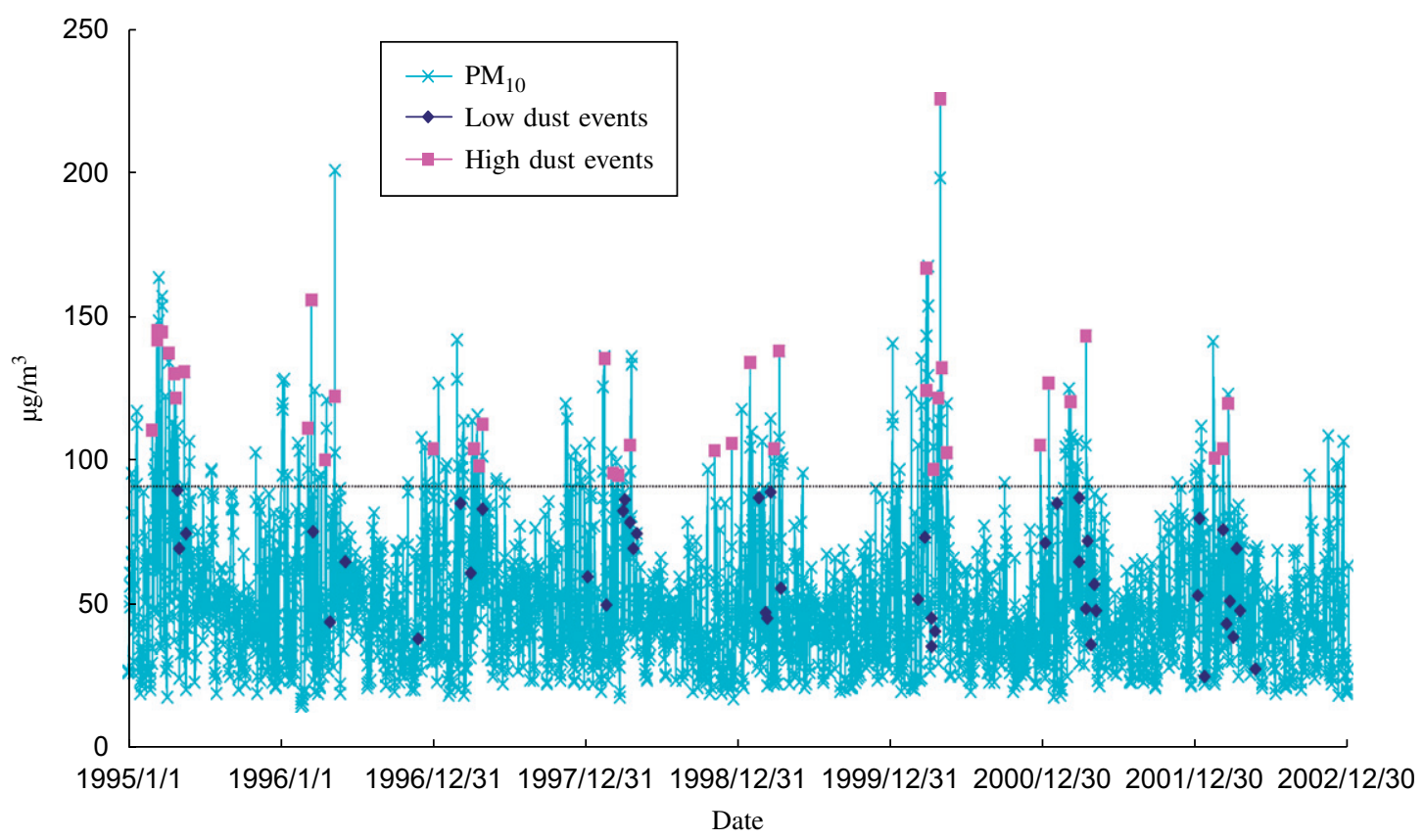

Fig. 1. Daily concentrations of $\mathrm{PM}_{10}$ for 85 Asian dust storms in Taipei, Taiwan, 1995-2002. Note: The blue dots are low dust events $\left(\leqslant 90 \mu \mathrm{g} / \mathrm{m}^{3}\right)$ and pink dots are high dust events $\left(>90 \mu \mathrm{g} / \mathrm{m}^{3}\right)$ in this study.

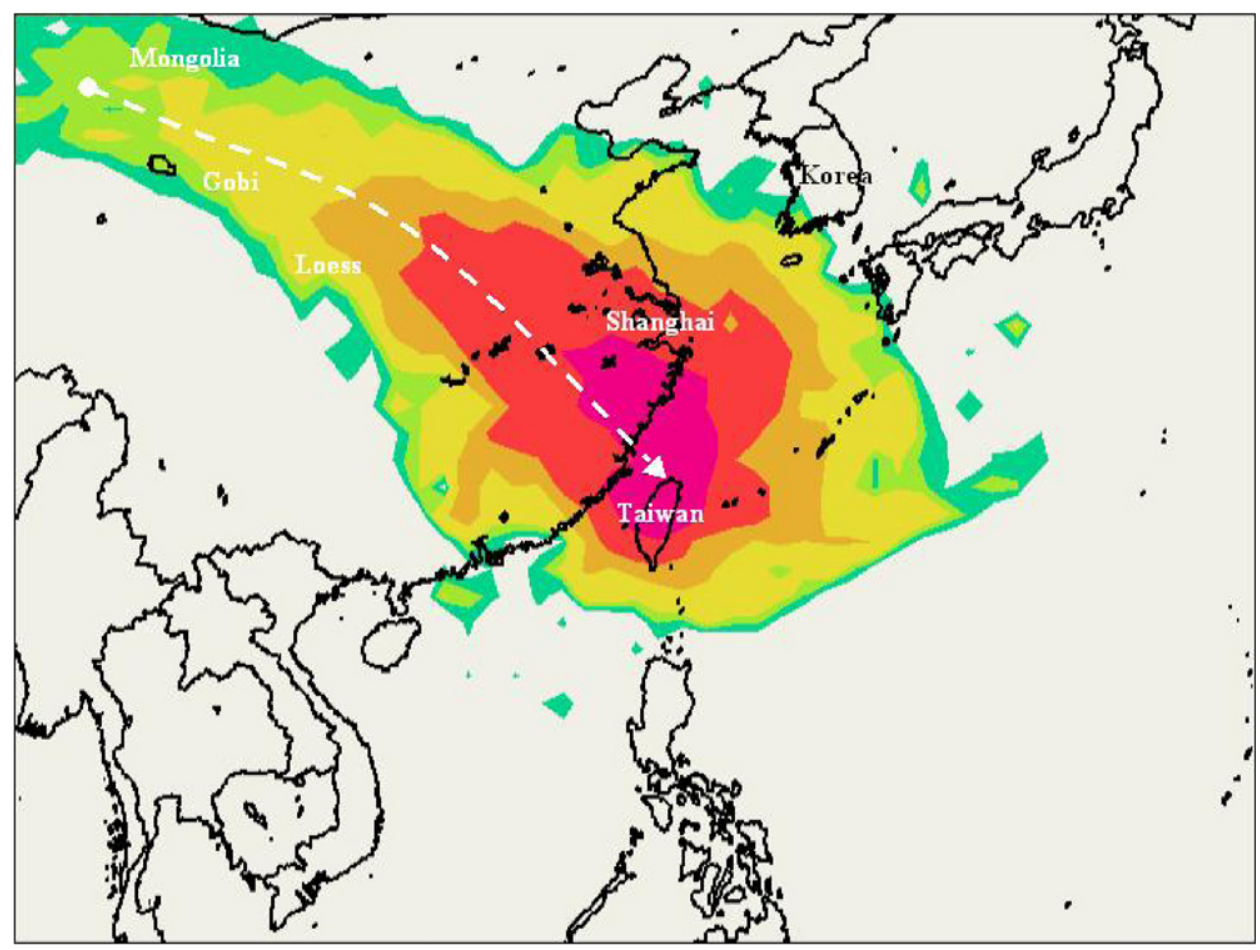

Fig. 2. Spatial distribution of 39 high dust events reaching Taipei, Taiwan, 1995-2002 based on modeling results of the U.S. National Ocean and Atmospheric Administration (NOAA) ARL HYSPLIT Model with National Centers for Environmental Prediction (NCEP) reanalysis datasets (http:// www.arl.noaa.gov/ready/hysplit4.html). Note: The colors indicate the frequency of spatial distribution of 39 high dust events: pink ( $\square$ ), $80 \%$; red ( $\square$ ), $70 \%$; brown ( $), 60 \%$; yellow ( $\square$ ), $50 \%$; green $(\square), 40 \%$; and light green $(\square), 30 \%$. 
levels less than a significance level of 0.05 in the singlepollutant models, were considered for further analyses in our multi-pollutant models. When there were several significant ORs at different day lags for one specific air pollutant, we used only the one with the maximum OR in the models. The air pollutants with significant ORs in single-pollutant models were, then, combined together in our multi-pollutant models. A significance level of 0.05 with two-side distribution was used to determine statistical significance in our models. Finally, we examined residuals plots to check the residuals' autoregressive effects and determine whether autoregressive terms should be added to remove serial correlations between the repeated daily measures in all single-pollutant and multi-pollutant Poisson models. The selection criterion of goodness of fit was assessed using Akaike's information criterion (AIC) to derive a best-fitted multiple-pollutants model. By applying air quality data of corresponding day lags before each dust event to our best-fitted multiple-pollutants model, we can obtain model-predicted emergency visits for all Asian dust events assuming dust storms were not present in Taipei. Then, a two-tail paired $t$-test was used to compare the difference between model-predicted emergency visits and observed emergency visits for all Asian dust events in Taipei. All data analyses were performed by SAS software procedure (version 8.0; SAS Institute Inc., Cary, NC), and a significance level of $5 \%$ was used.

\section{Results}

As shown in Fig. 1, there were 85 Asian dust storms reaching Taipei in 8 years between 1995 and 2002. The durations of storms consisted of 49 one-day events, 31 twoday events, and 5 three-day events among these 85 Asian dust events in Taipei. By excluding $\mathrm{PM}_{10}$ data of these storms-affecting days from calculation, the median value of daily $\mathrm{PM}_{10}$ concentration averaged over 16 TEPA monitoring stations was about $46 \mu \mathrm{g} / \mathrm{m}^{3}$ in Taipei during 1995-2002. We then used $90 \mu \mathrm{g} / \mathrm{m}^{3}$ of $\mathrm{PM}_{10}$, which was approximately 2 times of the median $\mathrm{PM}_{10}$ concentration, as a cut-off value to classify these 85 Asian dust events as "high dust events" and "low dust events" in Taipei. As indicated in Fig. 1, there were 39 high dust events (purple dots) and 46 low dust events (blue dots) in Taipei.

Fig. 2 shows spatial distribution of the trajectoryweighted main routes for the 39 high dust events in Taipei between 1995 and 2002. The general pathway of these dusttransported routes was southward and eastward from Mongolia through China to Taiwan. The dust-transported routes for $70-80 \%$ of these 39 high dust events covered an important industrial and urban area in China, including Jiangsu, Zhejiang, Anhui, Jiangxi, Hubei, Hunan, and Fujian provinces from north to south. For $50-60 \%$ of these 39 high dust events, the storm-affected areas extended even further north to Shandong Peninsula, southern Korean peninsula, and Kyushu, Japan, and further south to Jiangxi and Guangdong provinces, and Hong-Kong, China.

Table 2 summarizes the event-averaged air pollution levels, meteorological conditions, and number of emergency visits for ischaemic heart diseases, cerebrovascular diseases, and COPD during the Asian dust events and predust periods in Taipei. For the 39 pairs of high dust events, paired $t$-tests showed that $\mathrm{PM}_{10}$ concentrations in the dust events were significantly higher than those in the pre-dust periods by $77.2 \mu \mathrm{g} / \mathrm{m}^{3}$ per event. By contrast, there was no significant difference in $\mathrm{PM}_{10}$ between low dust events and their pre-dust periods. For both high and low dust events, there were marginal significant differences $(p$-value $<0.1)$

Table 2

Comparisons of event-averaged air pollution levels, meteorological variables, and emergency visits between Asian dust events and pre-event periods during 1995-2002 in Taipei, Taiwan (mean \pm S.D.)

\begin{tabular}{|c|c|c|c|c|c|c|}
\hline & \multicolumn{3}{|c|}{ High dust events ${ }^{\mathrm{a}}(N=39)$} & \multicolumn{3}{|c|}{ Low dust events ${ }^{\mathrm{a}}(N=46)$} \\
\hline & $\begin{array}{l}\text { Asian dust } \\
\text { events }\end{array}$ & $\begin{array}{l}\text { Pre-dust } \\
\text { periods }\end{array}$ & $\begin{array}{l}\text { Difference mean (confidence } \\
\text { intervals) }\end{array}$ & $\begin{array}{l}\text { Asian dust } \\
\text { events }\end{array}$ & $\begin{array}{l}\text { Pre-dust } \\
\text { periods }\end{array}$ & $\begin{array}{l}\text { Difference mean (confidence } \\
\text { intervals) }\end{array}$ \\
\hline \multicolumn{7}{|l|}{ Environmental conditions } \\
\hline $\mathrm{PM}_{10}\left(\mu \mathrm{g} / \mathrm{m}^{3}\right)$ & $122.7 \pm 24.4$ & $45.5 \pm 17.6$ & $77.2(68.4,90.0)$ & $61.1 \pm 17.8$ & $59.4 \pm 31.0$ & $1.5(-7.3,10.2)$ \\
\hline $\mathrm{O}_{3}(\mathrm{ppb})$ & $56.2 \pm 19.9$ & $48.1 \pm 18.9$ & $8.1(-0.8,17.0)$ & $49.8 \pm 16.6$ & $49.9 \pm 16.6$ & $-0.1(-0.4,0.2)$ \\
\hline $\mathrm{CO}(\mathrm{ppm})$ & $1.9 \pm 0.8$ & $1.7 \pm 0.7$ & $0.2(-0.1,0.5)$ & $1.6 \pm 0.6$ & $1.6 \pm 0.6$ & $0.0(-0.3,0.3)$ \\
\hline $\mathrm{NO}_{2}(\mathrm{ppb})$ & $34.9 \pm 10.3$ & $31.5 \pm 8.2$ & $3.5(-0.5,7.4)$ & $29.4 \pm 8.1$ & $29.5 \pm 7.8$ & $-0.1(-2.9,2.7)$ \\
\hline $\mathrm{SO}_{2}(\mathrm{ppb})$ & $6.7 \pm 4.9$ & $5.1 \pm 4.2$ & $1.6(-0.1,3.3)$ & $4.7 \pm 3.5$ & $4.5 \pm 3.4$ & $0.2(-0.9,1.2)$ \\
\hline Temperature $\left({ }^{\circ} \mathrm{C}\right)$ & $20.5 \pm 3.6$ & $19.6 \pm 4.1$ & $0.9(-0.5,2.3)$ & $20.5 \pm 3.7$ & $19.7 \pm 4.0$ & $0.8(-0.3,1.8)$ \\
\hline \multicolumn{7}{|l|}{ Emergency visits (case/event) } \\
\hline Cardiovascular diseases $^{\mathrm{a}}$ & $7.2 \pm 2.9$ & $5.7 \pm 2.5$ & $1.5(0.3,2.6)$ & $7.0 \pm 3.0$ & $6.7 \pm 3.3$ & $0.2(-0.9,1.2)$ \\
\hline Ischaemic heart diseases & $2.7 \pm 1.8$ & $2.0 \pm 1.6$ & $0.7(0.1,1.4)$ & $2.6 \pm 1.9$ & $2.8 \pm 2.2$ & $-0.3(-1.0,0.4)$ \\
\hline Cerebrovascular diseases & $4.4 \pm 2.3$ & $3.6 \pm 1.8$ & $0.7(0.1,1.3)$ & $4.4 \pm 2.1$ & $3.9 \pm 2.2$ & $0.5(-0.3,1.3)$ \\
\hline $\begin{array}{l}\text { Chronic obstructive pulmonary } \\
\text { diseases }^{\mathrm{a}}\end{array}$ & $5.4 \pm 2.1$ & $4.5 \pm 2.0$ & $0.9(0.1,1.7)$ & $5.3 \pm 2.4$ & $5.8 \pm 2.8$ & $-0.5(-1.5,0.5)$ \\
\hline
\end{tabular}

\footnotetext{
${ }^{a}$ High dust events: ambient averaged $\mathrm{PM}_{10}$ concentrations in Taipei are greater than $90 \mu \mathrm{g} / \mathrm{m}^{3}$ during storm-affecting periods; low dust events: ambient averaged $\mathrm{PM}_{10}$ concentrations in Taipei are less than $90 \mu \mathrm{g} / \mathrm{m}^{3}$ during storm-affecting periods; cardiovascular diseases: ischaemic heart diseases (ICD-9 410-411, 414) and cerebrovascular diseases (ICD-9 430-437); and chronic obstructive pulmonary diseases (ICD-9 496).
} 
in air pollution levels of $\mathrm{NO}_{2}, \mathrm{SO}_{2}, \mathrm{CO}$, and $\mathrm{O}_{3}$ between the dust events and their pre-dust periods. However, ambient temperatures during the dust events remained the same as those in the pre-dust periods. Paired $t$-tests also show emergency visits for cardiovascular diseases, ischaemic heart diseases, cerebrovascular diseases, and COPD during high dust events were 1.5 cases $(95 \%$ confidence intervals $=0.3-2.6), 0.7$ cases $(95 \%$ confidence intervals $=0.1-1.4), 0.7$ cases $(95 \%$ confidence intervals $=$ $0.1-1.3)$, and 0.9 cases $(95 \%$ confidence intervals $=$ $0.1-1.7)$ per event more than those in the pre-dust periods. By contrast, there was no significant difference in emergency visits for cardiovascular diseases, ischaemic heart diseases, cerebrovascular diseases, or COPD between 46 low dust events and their pre-dust periods.

By adding individual air pollutants and weather variables at 0-day to 7-day lags to our base models, we found only $\mathrm{PM}_{10}, \mathrm{PM}_{2.5}, \mathrm{TP}$, and DTP at certain day lags were associated with emergency visits for cardiovascular diseases. There were positive trends in the cardiovascular emergency visits and $\mathrm{NO}_{2}$ concentrations although their associations were not statistically significant. The bestfitted Poisson regression model to predict emergency visits for cardiovascular diseases without dust events is shown in Table 3. Accordingly, our best-fitted Poisson regression model can be expressed as: $\log \mu_{t}=\sum_{i=1995}^{2002} \alpha_{1_{i}}(\text { year })_{i}+$ $\beta_{1} X_{t-6}^{\mathrm{PM}_{2.5}}+\beta_{2} X_{t-3}^{\mathrm{PM}_{10}}+\beta_{3} X_{t-1}^{\mathrm{TP}}+\beta_{4} X_{t}^{\mathrm{DTP}}+\beta_{5} X_{t}^{\mathrm{NO}_{2}}$. In this

\section{Table 3}

The odds ratios of daily emergency visits for cardiovascular diseases for interquartile range change in environmental conditions without dust storm effect estimated by the best-fitted Poisson regression model in Taipei between 1995 and 2002

\begin{tabular}{lllr}
\hline Variable & Odds ratio & $95 \%$ confidence interval & $p$-value \\
\hline $\mathrm{PM}_{2.5}$ lagged 6 days & 1.024 & $(1.004,1.044)$ & 0.019 \\
$\mathrm{PM}_{10}$ lagged 3 days & 1.023 & $(1.003,1.041)$ & 0.019 \\
TP lagged 1 day & 0.938 & $(0.907,0.970)$ & $<0.001$ \\
$\mathrm{DTP}$ & 1.077 & $(1.022,1.135)$ & 0.005 \\
$\mathrm{NO}_{2}$ & 1.022 & $(0.999,1.046)$ & 0.057 \\
\hline
\end{tabular}

$\mathrm{PM}_{2.5}$, particulate matter less than $2.5 \mu \mathrm{m}$ in diameter; $\mathrm{PM}_{10}$, particulate matter less than $10 \mu \mathrm{m}$ in diameter; TP, temperature; DTP, daily difference temperature; and $\mathrm{NO}_{2}$, nitrogen dioxide.

Note: Cardiovascular diseases [International Classification of Disease, 9th revision-Clinical Modification (ICD-9-CM) 410-411, 414, 430-437].

The best-fitted Poisson regression model is

$$
\begin{aligned}
\log \mu_{t}= & \sum_{i=1995}^{2002} \alpha_{1_{i}}(\text { year })_{i}+\beta_{1} X_{t-6}^{\mathrm{PM}_{2.5}}+\beta_{2} X_{t-3}^{\mathrm{PM}_{10}} \\
& +\beta_{3} X_{t-1}^{\mathrm{TP}}+\beta_{4} X_{t}^{\mathrm{DTP}}+\beta_{5} X_{t}^{\mathrm{NO}_{2}}, \\
\alpha_{1995}= & 1.289, \alpha_{1996}=1.287, \alpha_{1997}=1.287, \alpha_{1998}=1.290, \alpha_{1999}=1.289, \\
\alpha_{2000}= & 1.671, \alpha_{2001}=1.614, \alpha_{2002}=1.655, \beta_{1}=0.001, \beta_{2}=0.001, \\
& \beta_{3}=-0.008, \beta_{4}=0.011, \beta_{5}=0.002 .
\end{aligned}
$$

The interquartile ranges of environmental data used to calculate odds ratios are: $19.7 \mu \mathrm{g} / \mathrm{m}^{3}$ for $\mathrm{PM}_{2.5}$ lagged 6 days, $25.4 \mu \mathrm{g} / \mathrm{m}^{3}$ for $\mathrm{PM}_{10}$ lagged 3 days, $8.1{ }^{\circ} \mathrm{C}$ for TP lagged 1 day, $4.2^{\circ} \mathrm{C}$ for DTP, and $9.6 \mathrm{ppb}$ for $\mathrm{NO}_{2}$, respectively. model, $\mu_{t}$ is emergency visits on day $t ; \sum_{i=1995}^{2002} \alpha_{1_{i}}(\text { year })_{i}$ is a matrix containing the time function of year; $X_{t}$ is the covariate matrix containing $\mathrm{PM}_{2.5}$ lagged 6 days, $\mathrm{PM}_{10}$ lagged 3 days, TP lagged 1 day, DTP, and $\mathrm{NO}_{2}$ on day $t$. The matrix of $\alpha$ and $\beta$ are coefficients for covariates matrix $\sum_{i=1995}^{2002} \alpha_{1_{i}}(\text { year })_{i}$ and $X_{t}$, respectively. As shown in Table 3, $\mathrm{PM}_{2.5}$ lagged 6 days, $\mathrm{PM}_{10}$ lagged 3 days, TP lagged 1 day, and DTP were all significantly associated with daily emergency visits for cardiovascular diseases. The odds ratios of daily emergency visits for cardiovascular diseases increased by $2 \%, 2 \%$, and $8 \%$, respectively, per IQR increase in $\mathrm{PM}_{2.5}$ lagged 6 days $\left(\mathrm{IQR}=19.7 \mu \mathrm{g} / \mathrm{m}^{3}\right), \mathrm{PM}_{10}$ lagged 3 days $\left(\mathrm{IQR}=25.4 \mu \mathrm{g} / \mathrm{m}^{3}\right)$, and DTP $(\mathrm{IQR}=$ $4.2^{\circ} \mathrm{C}$ ). One additional IQR increase in TP lagged 1 day $\left(\mathrm{IQR}=8.1^{\circ} \mathrm{C}\right)$ corresponded to $6 \%$ decrease in the odds ratio of emergency visits for cardiovascular diseases. A negative but not significant trend was observed between $\mathrm{NO}_{2}$ and daily emergency visits for cardiovascular diseases. By applying air quality data to our best-fitted Poisson regression model, we predicted 3.6-6.5 emergency visits for cardiovascular diseases for the 39 dust events assuming dust storms were not present in Taipei. The paired $t$-test between model-predicted and observed emergency visits for cardiovascular diseases showed that the observed 7.2 \pm 2.9 cases per event (mean \pm S.D.) during the 39 high dust events was significantly higher than the model-predicted $4.3 \pm 1.1$ cases per event if dust storms were not present in Taipei.

By using the optical particle counter in Supersite to continuously measure size-specific PM concentrations in Taipei during March 12-19, 2002, we observed a significant contrast in PMs size spectra between the pre-dust and the Asian dust storm periods for a typical example of the 39 high dust events in Taipei (Taiwan Environmental Protection Agency 2002a, b). The measurements of PM between 0.1 and $10 \mu \mathrm{m}$ per $48 \mathrm{~h}$ in three observational periods are summarized in Fig. 3. Submicron aerosols dominated PM in the pre-dust period (March 12-13) and 2 days before the dust event (March 16-17), while coarse aerosols (1-10 um) dominated PM in the dust-event period (March 18-19). The volume concentrations of coarse aerosols in the dustevent period (March 18-19) were approximately three-fold higher than those in the pre-dust period (March 12-13). The mass concentrations of $\mathrm{PM}_{2.5}$ and $\mathrm{PM}_{10}$ measured by two co-located TEPA-operated air monitoring stations showed that $\mathrm{PM}_{2.5}$ contributed about $61 \%$ in pre-dust period (March 12-13) but only 44\% in the dust-event period (March 18-19) to $\mathrm{PM}_{10}$ in Taipei metropolitan. During the dust storm period of (March 18-19), the concentrations of coarse fraction $\left(\mathrm{PM}_{10}-\mathrm{PM}_{2.5}\right)$ in all 16 air monitoring stations were from 22.4 to $104.5 \mu \mathrm{g} / \mathrm{m}^{3}$. Concurrently, the concentrations of four PM components, i.e. OC, EC, nitrates, and sulfates, measured by Supersite on March 18-19 were significantly higher than those on March 12-13. The event-averaged concentrations of OC, EC, nitrates, and sulfates were $8.3,3.2,4.0$, and $10.5 \mu \mathrm{g} / \mathrm{m}^{3}$ on March 18-19, respectively. By contrast, averaging 


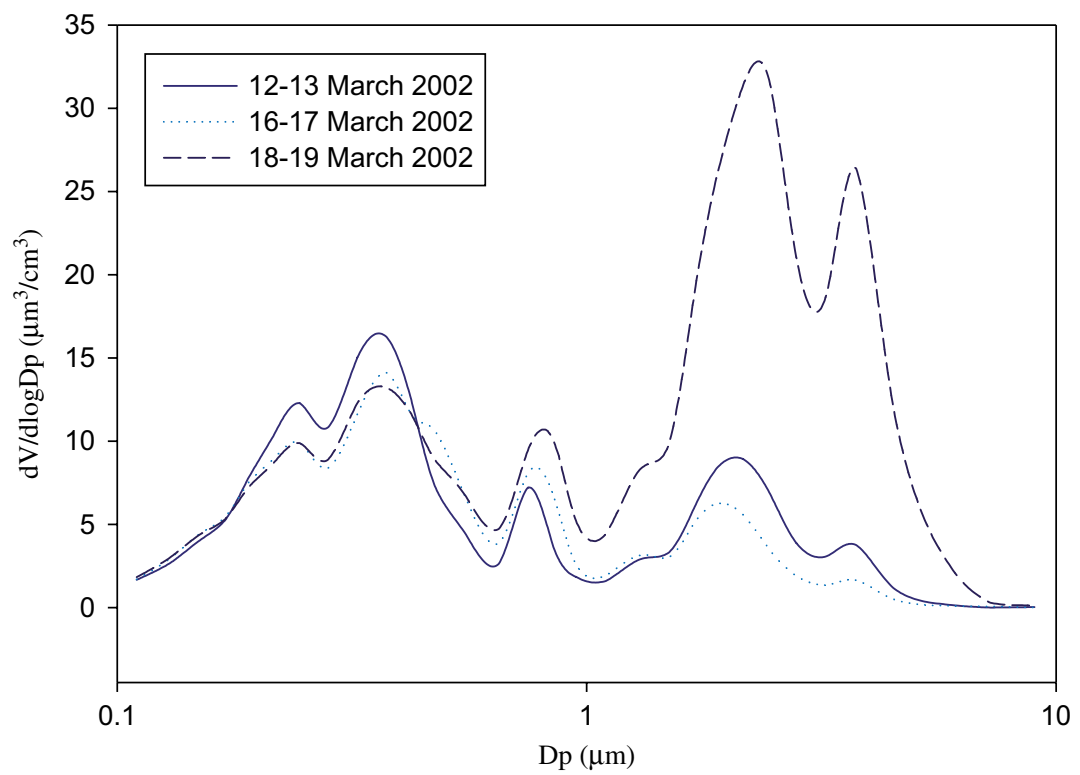

Fig. 3. Comparisons of size spectra of the ambient particulate matters collected on March 18-19 (an Asian dust event in Taipei), and on March 12-13 (pre-dust period) and March 16-17 (2 days before the dust event) in 2002 based on the measurement of particle volume concentrations with size resolution between 0.1 and $10 \mu \mathrm{m}$ in Supersite. Note: $\mathrm{d} V / \mathrm{d} \log D_{\mathrm{p}}$ indicates volume distributions of particles, on a logarithmic scale, as a function of particle diameter to display the wide range by size.

concentrations of $\mathrm{OC}, \mathrm{EC}$, nitrates, and sulfates were 6.2, $2.1,3.3$, and $7.7 \mu \mathrm{g} / \mathrm{m}^{3}$ on March $12-13$, respectively.

\section{Discussion}

This study provides evidence that Asian dust storms are associated with an increased number of emergency visits for cardiopulmonary diseases if $\mathrm{PM}_{10}$ concentrations are above $90 \mu \mathrm{g} / \mathrm{m}^{3}$ during the storm-affecting periods in Taipei. With an increase in $77.2 \mu \mathrm{g} / \mathrm{m}^{3} \mathrm{PM}_{10}$ per event, the emergency visits for cardiovascular diseases, ischaemic heart diseases, cerebrovascular diseases, and COPD during the Asian dust events are increased by 1.5 cases $(26 \%), 0.7$ cases $(35 \%), 0.7$ cases $(20 \%)$, and 0.9 cases $(20 \%)$ per event, respectively, compared to the pre-dust periods. The Poisson regression model predicted an even higher increase in emergency visits for cardiovascular diseases, which are 2.9 cases per event $(67 \%)$, by considering long-term trends of emergency visits and co-pollutants in the models. By better defining both exposure and outcome variables, using a longer observational period and time-series approach in this study, we are able to detect consistent effects of Asian dust storms on emergency visits for cardiopulmonary diseases in Taipei as opposed to previous studies (Chen and Yang, 2005; Yang et al., 2005). It should be noted that no increase in emergency visits for diseases for the 46 low dust events was comparable to no increase in pollution levels during these events compared to their pre-dust periods. Apparently, the air quality in Taipei was not deteriorated significantly by the low dust events to cause additional health effects. When the storm's length of stay was less than 1 day or there were concurrent terrestrial rains, the Asian dust storms' influence on increasing $\mathrm{PM}_{10}$ concentrations in Taipei were usually reduced.

Corresponding to the high dust events on March 18-19 in Taipei described in Fig. 3, an in vivo study on pulmonary hypertensive rats also shows that increases in total cell numbers and the proportion of neutrophil are associated with exposures to concentrated ambient particles for 4.5 or $6 \mathrm{~h}$ on the high dust event in Taipei (March 18-19, 2002) (Lei et al., 2004). Such findings of dust-induced lung inflammation and injury in experimental animals further indicate that Asian dust storms may also be able to induce similar inflammatory effects on the admitted patients for cardiopulmonary diseases in this study.

Although a two-mode distribution of PM is observed on both pre-dust and Asian dust storm days in Taipei, coarse PM during Asian dust events is significantly more abundant than that in the pre-dust periods and OC, EC, nitrates, and sulfates concentrations during Asian dust events are also all significantly higher than those in the pre-dust periods. As shown in Fig. 2, the main way of transport for Asian dust storms reaching Taipei covers at least seven provinces in China, which has many people, uses a lot of energy, and emits significant amount of air pollutants annually. It is estimated that China used about $18,189 \mathrm{PJ}$ (petajoule $\left(\mathrm{PJ}=10^{15} \mathrm{~J}\right)$ ) coal and $3396 \mathrm{PJ}$ oil, and emitted $20.4 \mathrm{Tg}$ (teragram, $10^{12} \mathrm{~g}$ ) $\mathrm{SO}_{2}$, $11.4 \mathrm{Tg}$ nitrogen oxides, $3820 \mathrm{Tg}$ carbon dioxide, $116 \mathrm{Tg}$ carbon monoxide, $38.4 \mathrm{Tg}$ methane, $17.4 \mathrm{Tg}$ nonmethane volatile organic compounds, $1.05 \mathrm{Tg}$ black carbon, $3.4 \mathrm{Tg}$ $\mathrm{OC}$, and $13.6 \mathrm{Tg} \mathrm{NH}_{3}$ in 2000 (Streets et al., 2003). China accounted for $58 \%$ coal use, $24 \%$ oil use, and $42 \%$ emissions of air pollutant in Asia in 2000. Such findings lead us to believe that coarse particles and certain chemical components contained in the long-range transported Asian 
dust storms are related to increase in emergency visits for cardiopulmonary diseases in Taipei during dust storms. It is likely that a certain amount of chemicals attached to the Asian dust may be from urban or industrial emissions in China. Our findings imply that countries around China should consider cross-border long-range transported air pollution in setting their own air pollution control policies, especially the three downwind countries of Asian dust storms, i.e. Korea, Japan, and Taiwan. An international cooperation of slowing land degradation in Mongolia and reducing emissions of air pollutants in China can help lower the impact of Asian dust storms on the air quality of dust storm-affecting areas. Based on our findings, Taiwan EPA has established a 2-day forecast and warning system on the web, TV, and radio to inform the general public of possibly poor air quality and to advise people with cardiovascular and respiratory disease of avoiding outdoor activities during the dust-event period.

One possible pathophysiological link between urban and industrial PM and cardiopulmonary morbidity is that alveolar inflammation provoked by inhaled particles, in addition to promoting exacerbations of lung disease, may exacerbate the autonomic function of the heart (Stone and Godleski, 1999) and subsequently contribute to a systemic inflammatory state, which may in turn be capable of activating haemostatic pathways, impairing vascular function, and atherosclerosis (Seaton et al., 1995).

Further studies, however, are still needed in order to answer following key yet unanswered questions raised by the findings in this study. What specific components in Asian dust are responsible for adverse health effects on a susceptible population? Are the health effects caused by the original mineral soils in the dust alone or the co-pollutants picked up in the dust air masses, such as synthetic organic chemicals, anthropogenic inorganic pollutants and trace metals, and microorganisms, on the transport routes? Will there also be adverse health effects for people having longterm exposures to Asian dust for years?

\section{Acknowledgment}

This study was supported by the research grants from Taiwan Environmental Protection Agency (EPA-93-FA1103-A232).

\section{References}

Chen, Y.S., Yang, C.Y., 2005. Effects of Asian dust storm events on daily hospital admissions for cardiovascular disease in Taipei, Taiwan. J. Toxicol. Environ. Health. A 68, 1457-1464.

Chen, Y., Cai, Q., Tang, H., 2003. Dust storm as an environmental problem in north China. Environ. Manage. 32, 413-417.

Chen, Y.S., Sheen, P.C., Chen, E.R., Liu, Y.K., Wu, T.N., Yang, C.Y., 2004. Effects of Asian dust storm events on daily mortality in Taipei, Taiwan. Environ. Res. 95, 151-155.

Chung, Y.S., Yoon, M.B., 1996. On the occurrence of yellow sand and atmospheric loadings. Atmos. Environ. 30, 2387-2397.
Department of Statistics, Ministry of the Interior of the Republic of China, 2005. Monthly bulletin of interior statistics. Available from: $\langle$ http://www.moi.gov.tw/stat/〉.

Dominici, F., Peng, R.D., Bell, M.L., Pham, L., McDermott, A., Zeger, S.L., Samet, J.M., 2006. Fine particulate air pollution and hospital admission for cardiovascular and respiratory diseases. JAMA 295, 1127-1134.

Duce, R.A., Unni, C.K., Ray, B.J., Prospero, J.M., Merrill, J.T., 1980. Long-range atmospheric transport of soil dust from Asia to the Tropical North Pacific: temporal variability. Science 209, 1522-1524.

Fan, X.B., Okada, K., Nimura, N., Kai, K., Arao, K., Shi, G.Y., Qin, Y., Mitsuta, Y., 1996. Mineral particles collected in China and Japan during the same Asian dust-storm event. Atmos. Environ. 30, 347-351.

Garrison, V.H., Shinn, E.A., Foreman, W.T., Griffin, D.W., Holmes, C.W., Kellogg, C.A., Majewski, M.S., Richardson, L.L., Ritchie, K.B., Smith, G.W., 2003. African and Asian dust: from desert soils to coral reefs. BioScience 53, 469-480.

Husar, R.B., Tratt, D.M., Schichtel, B.A., Falke, S.R., Li, F., Jaffe, D., Gassó, S., Gill, T., Laulainen, N.S., Lu, F., Reheis, M.C., Chun, Y., Westphal, D., Holben, B.N., Gueymard, C., McKendry, I., Kuring, N., Feldman, G.C., McClain, C., Frouin, R.J., Merrill, J., DuBois, D., Vignola, F., Murayama, T., Nickovic, S., Wilson, W.E., Sassen, K., Sugimoto, N., Malm, W.C., 2001. Asian dust events of April 1998. J. Geophys. Res. 106, 18316-18330.

Kwon, H.J., Cho, S.H., Chun, Y., Legarde, F., Pershagen, G., 2002. Effects of the Asian dust events on daily mortality in Seoul, Korea. Environ. Res. 90, 1-5.

Lei, Y.C., Chan, C.C., Wang, P.Y., Lee, C.T., Cheng, T.J., 2004. Effects of Asian dust event particles on inflammation markers in peripheral blood and bronchoalveolar lavage in pulmonary hypertensive rats. Environ. Res. 95, 71-76.

Lin, T.H., 2001. Long-range transport of yellow sand to Taiwan in spring 2000: observed evidence and simulation. Atmos. Environ. 35, 5873-5882.

Moulin, C., Lambert, C.E., Dulac, F., Dayan, U., 1997. Control of atmospheric export of dust from North Africa by the North Atlantic oscillation. Nature 387, 691-694.

Seaton, A., MacNee, W., Donaldson, K., Godden, D., 1995. Particulate air pollution and acute health effects. Lancet 345, 176-178.

Shinn, E.A., Smith, G.W., Prospero, J.M., Betzer, P., Hayes, M.L., Garrison, V.H., Barber, R.T., 2000. African dust and the demise of Caribbean coral reefs. Geophys. Res. Lett. 27, 3029-3032.

Stone, P.H., Godleski, J.J., 1999. First steps toward understanding the pathophysiologic link between air pollution and cardiac mortality. Am. Heart. J. 138, 804-807.

Streets, D.G., Bond, T.C., Carmichael, G.R., Fernandes, S.D., Fu, Q., He, D., Klimont, Z., Nelson, S.M., Tsai, N.Y., Wang, M.Q., Woo, J.H., Yarber, K.F., 2003. An inventory of gaseous and primary aerosol emissions in Asia in the year 2000. J. Geophys. Res. 108, 8809.

Su, T.C., Chan, C.C., Liau, C.S., Lin, L.Y., Kao, H.L., Chuang, K.J., 2006. Urban air pollution increases plasma fibrinogen and plasminogen activator inhibitor-1 levels in susceptible patients. Eur. J. Cardiovasc. Prev. Rehabil. 13, 849-852.

Taiwan Environmental Protection Agency, 2002a. Health risk assessment on ambient air pollution of particles in Taiwan (EPA Publication EPA-91-FA11-03-91DF02).

Taiwan Environmental Protection Agency, 2002b. Aerosol supersite quality assurance on operation and maintenance (EPA Publication EPA-91-L105-02-206).

Var, F., Narita, Y., Tanaka, S., 2000. The concentration, trend and seasonal variation of metals in the atmosphere in 16 Japanese cities shown by the results of National Air Surveillance Network (NASN) from 1974 to 1996. Atmos. Environ. 34, 2755-2770.

Yang, C.Y., Chen, Y.S., Chiu, H.F., Goggins, W.B., 2005. Effects of Asian dust storm events on daily stroke admissions in Taipei, Taiwan. Environ. Res. 99, 79-84. 